\title{
PROGRAM PENCEGAHAN ANEMIA BAGI WANITA MASA PRAKONSEPSI DI WILAYAH KERJA PUSKESMAS SIDEMEN KABUPATEN KARANGASEM
}

\author{
L.S. Ani ${ }^{1}$, I.W. Weta ${ }^{2}$, N.W.A. Utami ${ }^{3}$, W. Suranadi ${ }^{4}$, K. Suwiyoga ${ }^{5}$
}

\begin{abstract}
ABSTRAK
Kecamatan Sidemen memiliki masalah anemia di mana kejadian anemia pada ibu hamil adalah $60,5 \%$. Meskipun Puskesmas Sidemen telah melaksanakan program kesehatan ibu dan anak melalui pemberian tablet $90 \mathrm{Fe}$ kepada ibu hamil, tetapi kejadian anemia dan masalah gizi lainnya masih tinggi. Ini mungkin karena anemia dan atau kekurangan gizi telah terjadi dalam periode prakonsepsi. Anemia dapat diatasi dengan pemberian tablet besi $200 \mathrm{mg}$ selama 90 hari. Hanya saja kepatuhan wanita dalam tablet besi masih sangat rendah yaitu sebesar 35\%. Selain itu, variasi sistem pelayanan dari tenaga kesehatan spesialis dan bidan cukup besar dalam hal dosis dan waktu pemberian tablet besi. Ini tentu akan berdampak pada keberhasilan program pencegahan anemia untuk semua wanita hamil. Berdasarkan itu, program pencegahan anemia pada periode prakonsepsi perlu dilaksanakan sebagai alternatif dari program yang ada. Pengabdian ini dilakukan dengan memberikan informasi tentang pentingnya mengkonsumsi tablet besi selama kehamilan pada wanita yang berprasangka dan juga kepada petugas kesehatan tentang cara yang efektif dan dosis tablet zat besi. Hasil dari pengabdian menemukan bahwa kejadian anemia pada wanita selama periode prakonsepsi sangat tinggi, yaitu 40,2\%. Ceramah tentang anemia meningkatkan pengetahuan wanita yang prasekognisi tentang anemia sebesar 60\%. Dan hasil FGD pada bidan menemukan bahwa tidak ada program administrasi tablet besi pada kelompok wanita pra-konsepsi. Jadi disarankan untuk memberikan tablet besi pada wanita prasekognisi karena pencegahan lebih baik daripada pengobatan
\end{abstract}

Kata kunci: Anemia, Tablet Besi, Kepatuhan, Layanan Kesehatan Masyarakat, Program Gizi Masyarakat

\begin{abstract}
Sidemen sub-district has anemia problem where the incidence of anemia in pregnant mother is $60.5 \%$. Although Sidemen Community Health Center has implemented maternal and child health program through giving $90 \mathrm{Fe}$ tablets to pregnant women, but the incidence of anemia and other nutritional problems is still high. This is presumably because anemia and or nutritional deficiencies have occurred in the preconception period. Anemia can be overcome by administration of $200 \mathrm{mg}$ iron tablets for 90 days. It's just adherence of women in iron tablets is still very low that is equal to $35 \%$. In addition, the variation of service system from health personnel specialist and midwife is quite large in dosage and time of administration of iron tablet. This will certainly impact on the success of anemia prevention programs for all pregnant women. Based on that, the prevention program of anemia in the preconception period needs to be implemented as an alternative to the existing program. This devotion is done by giving information about the importance of consuming iron tablets during pregnancy in preconceptive women and also to health workers on the effective ways and doses of iron tablets. The result of devotion found that the incidence
\end{abstract}

${ }^{1}$ Departemen IKMKP Fakultas Kedokteran Universitas Udayana, Email: luhseriani@yahoo.com

${ }^{2}$ Program Studi IKM Fakultas Kedokteran Universitas Udayana

${ }^{3}$ Departemen DME Fakultas Kedokteran Universitas Udayana

${ }^{4}$ Departemen Anestesi dan Reanimasi Fakultas Kedokteran Universitas Udayana

${ }^{5}$ Bagian Obstetri Ginekologi Fakultas Kedokteran Universitas Udayana 
of anemia in women during preconception period is very high, that is $40.2 \%$. Lectures on anemia increase preconceptive women's knowledge of anemia by $60 \%$. And FGD results on the midwife found that there is no iron tablet administration program in pre-conception women group. So it is advisable to give iron tablets in preconseption women because prevention is better than treatment

Keywords : Anemia, Iron Tablet, Compliance, Community Health Service, Community Nutrition Program

\section{PENDAHULUAN}

Anemia dan atau defisiensi besi (ADB) masih merupakan masalah kesehatan yang pentingterkait prevalenisnya yang tinggi serta efek sampingnya, terutama pada wanita hamil. Bebagai studi melaporkan bahwa anemia pada wanita hamil dapat memberikan efek buruk terhadap output kehamilan seperti BBLR, stillbirth,kelahiran preterm, perdarahan masa kehamilan, post partum, bahkan mengarah kepada kematian ibu.Berdasarkan hasil Riset Kesehatan Dasar (Riskesdas) ${ }^{1}$ tahun 2013, prevalensi anemia pada ibu hamil di Indonesia dilaporkan sebesar 37,1\%. Upaya pencegahan melalui program pemberian tablet Fe pada seluruh ibu hamil pada masa kehamilan belum memenuhi harapan, dimana cakupan pemberian tablet besi di Indonesia pada tahun 2012 hanya sebesar $85 \%$. Sedikit lebih tinggi dibandingkan dengan cakupan pemberian tablet tambah darah pada wanita hamil tahun 2011 yaitu sebesar 83,3\%.

Kejadian anemia pada ibu hamil di Bali bervariasi tergantung metode dan wilayah penelitian di laksanakan. Secara umum kejadian anemia pada wanita hamil di Bali sebesar 46,2\% ${ }^{2}$. Diantara Kabupaten di Provinsi Bali, angka kejadian anemia pada wanita hamil paling besar di Kabupaten Karangasem yaitu sebesar 60,5\% dan KEK sebesar $19 \%{ }^{3}$. Disamping itu Kabupaten Karangasem juga menyimpan beberapa masalah gizi paling banyak dibandingkan dengan kabupaten lainnya di Provinsi Bali, masalah kurang gizi dan gizi buruk pada balita, kejadian kurang energi kronis pada ibu hamil.

Kecamatan Sidemen sebagai salah satu wilayah di Kabupaten Karangasem juga memiliki masalah yang sama. Kejadian anemia pada ibu hamil sebesar $60,5 \%$ KEK sebesar $21 \%$, gizi kurang pada balita 8,1\%, gizi buruk 1,2\%, dan gizi lebih sebesar 1,7\%. Wilayah sidemen juga menyimpan masalah stunting pada anak usia bawah tiga tahun sebesar $15,7 \%$

Meskipun Puskesmas Sidemen sudah melaksaan program KIA dan perbaikan gizi keluarga melalui pemberikan 90 tablet Fe kepada ibu hamil, serta pemberian PMT pada balita dengan gizi kurang dan buruk, tetapi kejadian anemia dan masalah gizi lainnya masih tinggi.

Hal ini diduga karena anemia dan atau kekurangan nutrisi sudah terjadi pada masa preconsepsi.

Masa prakonsepsi diukur pada 1 tahun setelah melahirkan dimana pada masa ini sangat merefleksikan status nutrisi pada wanita fertile ${ }^{4}$. Sedangkan, masa perikonsepsi adalah periode mulai fertil sampai stage awal kehamilan ${ }^{5}$.

Berdasarkan hal tersebut maka pengabdian ini diselenggarakan untuk menurunkan kejadian anemia pada wanita masa prakonsepsi atau pada masa hamil.

\section{METODE PEMECAHAN MASALAH}

Alternatif pemecahan masalah anemia pada wanita prakonsepsi di wilayah kerja Puskesmas Sidemen terdiri atas (1) Penyuluhan anemia bagi wanita masa prakonsepsi di wilayah kerja Puskesmas Sidemen Kabupaten Karangasem. (2) Fokus group discusion bagi tenaga kesehatan (bidan dan dokter) tentang pedoman pemberian tablet besi bagi wanita masa prahami dan wanita hamil. (3) Deteksi dini anemia atau pemeriksaan kadar hemoglobin bagi wanita masa prakonsepsi di wilayah kerja Puskesmas Sidemen 
Kabupaten Karangasem serta (4) Pemberian tablet besi 200mg sebanyak 90 tablet selama 3 bulan bagi wanita masa prakonsepsi dengan anemia.

\section{METODE PELAKSANAAN}

Penggabdian ini dilaksanakan dengan beberapa kegiatan diantaranya (1) memberikan ceramah tentang anemia, dampak buruknya serta pencegahannya bagi wanita masa prakonsepsi. (2) Pemeriksaan kadar hemoglobin bagi wanita masa prakonsepsi untuk mendektesi kejadian anemia. (3). FGD bagi tenaga kesehatan (bidan dan Dokter) untuk menyamakan persepsi tentang penberian tablet besi pada wanita masa prakonsepsi (4). Melakukan pedampingan kegiatan program pencegahan anemia bagi wanita masa prakonsepsi setiap 2 bulan sekali, selama 3 kali berturut turut.

\section{HASIL DAN PEMBAHASAN}

a. Ceramah tentang anemia,dampak buruknya serta pencegahannya bagi wanita masa prakonsepsi.

Ceramah ini di ikuti oleh 37 wanita prakonsepsi. Mereka tampak antusias mendengarkan materi yang disampaikan oleh penceramah. Berdasarkan hasi pre dan posttest yang di lontarkan secara lisan, tampak pengetahuan wanita prakonsepsi meningkat. Pada ppre test peserta hampir tidak mampu menjawab pertanyaan penceramah. Sedangkan pada posttest mereka mampu menjawab 3 dari 5 pertanyaan sehingga dapat disimpulkan pengetahuan wanita prakonsepsi meningkat sebesar $60 \%$.

Ceramah tentang anemia yang dilakukan pada program pencegahan anemia di desa sangkan Gunung kabupaten karangasem telah meningkatkan pengetahuan wanita prakonsepsi tentang anemia sebesar 30,1 point. Hal ini memberikan gambaran bahwa masyarakat khususnya wanita prakonsepsi sangat antusias mendengarkan ceramah yang diberikan. Selain itu pengetahuan tentang dampak negatif anemia juga menambah keingintahuan masyarakat tentang upaya pencegahan anemia yang dapat mereka lakukan. Upaya ceramah ini tidak cukup dilaksanakan sekali oleh karena ingatan masyarakat akan berkurang bila tidak ada penyegaran pengetahuan kembali sehingga program ini sebaiknya dilakukan secara rutin untuk terus meningkatkan pengetahuan masyarakat tentang anemia bahkan mereka mampu berupaya secara mandiri melakukan pencegahan kejadian anemia.

b. Pemeriksaan kadar hemoglobin bagi wanita masa prakonsepsi untuk mendektesi kejadian anemia.

Dari hasil pemeriksaan kadar hemoglobin didapatkan sebesar 43,2\% wanita prakonsepsi mengalami anemia yaitu 15 dari 37 wanita masa prakonsepsi yang di test kadar hemoglobinnya. Angka ini tentu sangat besar dibandingkan dengan angka anemia secara nasional yaitu sebesar 18\%. Sehingga program pencegahan anemia tetap di lakukan untuk menurunkan kejadian anemia pada masa prakonsepsi dan pada saat mereka engalami kehamilan.

Pada wanita prakonsepsi yang mengalami anemia diberikan tablet penambah darah sebanyak 10 biji yang dianjurkan untuk dikonsumsi 1 tablet perhari. Dan bila kondisi berlanjut mereka disarankan untuk mendatanga layanan kesehatan seperti puskesmas ataupun dokter praktek suasta

Sebanyak 37 wanita prakonsepsi yang turut berpartisipasi dilakukan pretest dan posttest tentang anemia. Score nilai jawaban benar pada pretest sebesar 22,1, sedangkan score jawaban benar pada postest adalah 52,25 . Hal ini menunjukkan adanya peningkatan pengetahuan tentang anemia pada wanita prakonsepsi sebesar 30,1. Secara lebih detail peningkatan pengetahuan tentang anemia ditampilkan pada tabel 1. 
Tabel 1. Pretest Dan Posttest Ceramah Anemia Pada Wanita Prakonsepsi

\begin{tabular}{|l|c|c|c|c|}
\hline \multirow{2}{*}{ Pertanyaan } & \multicolumn{2}{c|}{ Pretest } & \multicolumn{2}{c|}{ Posttest } \\
\cline { 2 - 5 } & \multicolumn{2}{c|}{ Jawaban Benar } & \multicolumn{2}{c|}{ Jawaban Benar } \\
\cline { 2 - 5 } & $\mathbf{n}$ & $\mathbf{\%}$ & $\mathbf{n}$ & $\mathbf{\%}$ \\
\hline Pengertian anemia & 2 & 5,4 & 16 & 43,2 \\
\hline Penyebab anemia & 3 & 8,1 & 18 & 48,4 \\
\hline Upaya pencegahan anemia & 24 & 64,8 & 35 & 94,6 \\
\hline Jenis makanan yang mengandung zat besi tinggi & 11 & 29,7 & 18 & 48,4 \\
\hline Jenis makanan yang mendorong penyerapan zat besi & 4 & 10,8 & 14 & 37,8 \\
\hline Jenis makanan yang menghambat penyerapan zat besi & 5 & 13,5 & 15 & 40,5 \\
\hline
\end{tabular}

Tabel 2 menggambarkan karakteristik dari wanita prakonsepsi yang terlibat dalam program pencegahan anemia. Sebesar 45,9\% wanita prakonsepsi berada pada kategori usia 20-35 tahun, hanya sebesar 35\% berpendidikan tinggi, sebesar 56,7\% bekerja, sebesar 56,4\% memiliki anak lebih dari 2, sebesar 2,1\% mengalami Kurang Energi Kronis (KEK) dan sebesar 64,9\% mengaku memiliki keluhan gejala anemia.

Tabel 2. Karakteristik Wanita Prakonsepsi

\begin{tabular}{|c|c|c|}
\hline \multicolumn{1}{|c|}{ Variabel } & n & \% \\
\hline Usia Ibu (tahun) & 5 & 13,5 \\
\hline$<20$ & 17 & 45,9 \\
\hline $20-35$ & 15 & 40,5 \\
\hline$>35$ & & 5,4 \\
\hline Pendidikan & 2 & 32,4 \\
\hline SD & 12 & 48,6 \\
\hline SMP & 18 & 13,5 \\
\hline SMA & 5 & 56,7 \\
\hline Perguruan tinggi & 21 & 43,3 \\
\hline Pekerjaan & 16 & \\
\hline Bekerja & & 40,5 \\
\hline Tidak Bekerja & 15 & 56,45 \\
\hline Paritas & 22 & \\
\hline$<2$ & & 8,1 \\
\hline$\geq 2$ & 3 & 91,9 \\
\hline KEK & 34 & 64,9 \\
\hline Ya & & 35,1 \\
\hline Tidak & 24 & \\
\hline Keluhan anemia & 13 & \\
\hline Ya & & \\
\hline Tidak & & \\
\hline
\end{tabular}

Berdasarkan hasil pemeriksaan kadar hemoglobin didapatkan sebanyak 43,2\% wanita prakonsepsi mengalami anemia (Tabel 3) 
Tabel 3. Kejadian Anemia Pada Wanita Prakonsepsi

\begin{tabular}{|l|c|c|}
\hline \multicolumn{1}{|c|}{ Kejadian Anemia } & n & \% \\
\hline Ya & 16 & 43,2 \\
\hline Tidak & 21 & 56,8 \\
\hline
\end{tabular}

Wanita prakonsepsi dengan anemia cendrung ditemukan pada wanita dengan usia $>35$ tahun (40\%), tingkat pendidikan rendah $(53,3 \%)$, tidak memiliki pekerjaan $(56,2 \%)$, memiliki anak $<2$ orang (40\%), dan memiliki keluhan anemia $(62,5 \%)$. Secara detai kejadian anemia berdasarkan karakteristik wanita prakonsepsi ditampilkan pada tabel 4.

Tabel 4. Kejadian Anemia Berdasarkan Karakteristik Wanita Prakonsepsi

\begin{tabular}{|c|c|c|c|c|c|}
\hline \multirow{3}{*}{\multicolumn{2}{|c|}{ Variabel }} & \multicolumn{4}{|c|}{ Kejadian anemia } \\
\hline & & \multicolumn{2}{|c|}{ Ya $(n=16)$} & \multicolumn{2}{|c|}{ Tidak $(n=21)$} \\
\hline & & Jumlah & $\%$ & Jumlah & $\%$ \\
\hline \multirow{3}{*}{ Usia Ibu (tahun) } & $<20$ & 2 & 40 & 3 & 60 \\
\hline & $20-35$ & 8 & 47,0 & 9 & 53,0 \\
\hline & $>35$ & 9 & 60 & 6 & 40 \\
\hline \multirow{2}{*}{ Pendidikan } & Rendah & 8 & 53,3 & 6 & 46,7 \\
\hline & Tinggi & 9 & 39,1 & 14 & 60,9 \\
\hline \multirow{2}{*}{ Pekerjaan } & Bekerja & 11 & 52,4 & 10 & 47,6 \\
\hline & Tidak bekerja & 9 & 56,2 & 7 & 43,8 \\
\hline \multirow{2}{*}{ Paritas } & $<2$ & 6 & 40 & 9 & 60 \\
\hline & $\geq 2$ & 8 & 36,7 & 14 & 63,3 \\
\hline \multirow{2}{*}{ KEK } & $\mathrm{Ya}$ & 0 & 0 & 3 & 100 \\
\hline & Tidak & 8 & 25 & 26 & 75 \\
\hline \multirow{2}{*}{ Keluhan anemia } & $\mathrm{Ya}$ & 15 & 62,5 & 9 & 37,5 \\
\hline & Tidak & 7 & 53,8 & 6 & 46,2 \\
\hline
\end{tabular}

Berdasarkan hasil pemeriksaan kadar hemoglobin pada wanita prakonsepsi didapatkan sebanyak 43,2\% mengalami anemia. Angka ini tentu sangat besar jika dibandingkan dengan kejadian anemia di Indonesia yaitu sebesar $37,1 \%$. Anemia disebabkan oleh adanya kehilangan zat besi karena perdarahan, faktor nutrisi, peningkatan kebutuhan zat besi serta gangguan absorbsi besi. Kehilangan darah dapat terjadi oleh karena pendarahan menahun yang bersumber dari saluran cerna dan infeksi cacing tambang. Pada wanita dapat terjadi perdarahan pervaginam oleh karena menorhagia dan metrorhagia. Faktor nutrisi sebagai penyebab anemia adalah kurangnya jumlah zat besi total dalam makanan dan kualitas besi dengan bioavailibilitas rendah. Sebagian besar masyarakat di dusun sangkan gunung mengkonsumsi makanan yang banyak mengandung serat, rendah vitamin $\mathrm{C}$ serta rendah daging, dimana jenis makanan tersebut diketahui memiliki kualitas besi rendah dan tingkat absorbsinya juga rendah. Kondisi ini akan bertambah buruk jika dialami oleh kelompok wanita dengan kebutuhan zat besi tinggi seperti wanita hamil dan menyusui.

Wanita prakonsepsi dengan anemia cendrung ditemukan pada wanita dengan usia >35 tahun (40\%), tingkat pendidikan rendah $(53,3 \%)$, tidak memiliki pekerjaan $(56,2 \%)$, memiliki anak $<2$ orang $(40 \%)$, dan memiliki keluhan anemia $(62,5 \%)$. Usia diatas 35 tahun adalah usia risiko tinggi bila mengalami kehamilan sehingga sangat diperlukan upaya deteksi dini anemia untuk calon ibu hamil khususnya pada kelompok risiko tinggi. Pada usia diatas 35 tahun cendrung sudah memiliki anak lebih dari 2 orang. 
Banyaknya jumlah anak yang dilahirkan serta jarak anak mempengaruhi cadangan besi tubuh pada wanita prakonsepsi, semakin banyak anak maka cadangan besi tubuh yang diperlukan juga meningkat. Sehingga sangat di sarankan untuk mengatur jarak kelahiran untuk memenuhi cadangan besi tubuh selama hamil ${ }^{6}$.

Gejala anemia sering tidak dikenali sebagai suatu masalah kesehatan oleh wanita prakonsepsi, dari hasil pengukuran didapatkan kejadian anemia didahului denganadanya keluhan seperti letih, lesu, pusing kepala serta cepat lelah. Kondisi tersebut akan menurunkan produktivitas kerja dari wanita prakonsepsi, sehingga upaya deteksi dini anemia diperlukan untuk mencegah anemia dan meningkatkan produktivitas kerja wanita prakonsepsi ${ }^{7}$.

Berdasarkan hasil FGD didapatkan bahwa hampir semua bidan menyatakan bahwa program pemberian tablet besi hanya diberikan pada wanita yang sudah hamil. Sedangkan pada kelompok wanita pra atau sebelum hamil tidak ada programnya. Untuk remaja, tablet besi diberikan 10 tablet dan diminum pada saat haid. Program pemberian tablet besi pada remaja berkoordinasi dengan program Usaha Kesehatan Sekolah, sehingga bagi remaja yang tidak sekolah, ada kemungkinan tidak tersentuh oleh program pemberian tablet besi.

Bagi wanita hamil, tablet besi diberikan sebanyak 90 tablet selama hamil, dan pemberian diberikan sejak awal kehamilan secara bertahap sesuai dengan jadwal wanita hamil ANC. Meskipun demikian para bidan tidak pernah memastikan atau memonitor apakah tablet besi tersebut dikonsumsi atau tidak.

Berdasarkan hal tersebut perlu adanya perbaikan metode pemberian tablet besi pada wanita hamil untuk menurunkan kejadian anemia pada wanita hamil serta mencegah dampak negatif anemia pada kehamilan.

\section{SIMPULAN DAN SARAN}

\subsection{Simpulan}

Pengetahuan wanita prakonsepsi tentang anemia masih rendah dengan nilai score tingkat pengetahuan sebesar 52,25. Berdasarkan hasil pemeriksaan kadar hemoglobin didapatkan sebanyak 43,2\% wanita prakonsepsi mengalami anemia. Wanita prakonsepsi dengan anemia cendrung ditemukan pada wanita dengan usia $>35$ tahun (40\%), tingkat pendidikan rendah (53,3\%), tidak memiliki pekerjaan $(56,2 \%)$, memiliki anak $<2$ orang $(40 \%)$, dan memiliki keluhan anemia $(62,5 \%)$.

\subsection{Saran}

Upaya peningkatan pengetahuan wanita prekonsepsi tentang anemia perlu dilaksanakan secara rutin untuk tetap mengingatkan akan bahaya anemia dalam produktivitas kerja ataupun dampak buruk anemia pada kehamilan. Selain itu upaya deteksi dini anemia juga diperlukan untuk penanganan lebih awal.

\section{UCAPAN TERIMAKASIH}

Ucapan terimakasih diberikan kepada Kepala dan seluruh staf Puskesmas Sidemen Kabupaten Karangasem, Ketua LPPM Universitas Udayana selaku penyandang dana serta masyarakat Desa Sangkan Gunumg atas partisipasinya dalam kegiatan pengabdian ini 


\section{DAFTAR PUSTAKA}

Badan Penelitian dan Pengembangan Kesehatan Kementerian RI . 2013. Riset Kesehatan Dasar(Riskesdas)

2013.Diakses: 19 Oktober 2014, dari http://www.depkes.go.id/resources/download/general/Hasil\%20Riskesdas\%20 2013.pdf.

Ani LS., Bakta M., Suryadhi INT., Bagiada N. 2010. Kadar feritin dan hemoglobin pada wanita pasangan pengantin baru di Provinsi Bali. Jurnal Gizi dan Pangan Vol 5, No 1:26

Swandewi PA., Muliawan PA., Sawitri AAS., Septarini NW. 2011. Anemia dan kurang energi kronoi (KEK) pada ibu rumah tangga di Desa Munti Gunung Karangasem. Jurnal Ilmu Gizi vol 2 no 1: 22-26.

Gonzalez-Casanova I., Nguyen P., Wei Hao., Hoa Pham., Truong T., Nguyen S., Martorell R., and Ramakrishnan U. 2014. Preconception anemia and birth outcome in Vietnam. The FASEB Journal vol 28 no 1 Supplement 804.6

Cetin., Berti C., Calabrese S. 2010. Role of Micronutrients in the periconceptional period. Hum. Reprod. Update. 16 (1):80-95

Madanijah S., Briawan., Rimbawan., Zulaikhah Z., Andarwulan N., Nuraida L., Sundjay T., Murti L., Shah P., Bindels J.,2016. Nutritional status of pre-pregnant and pregnant women residing in Bogor district, Indonesia: a cross-sectional dietary and nutrient intake study. Br J Nutr. Jul;116 Suppl 1:S57-66 